\title{
Islet Amyloid Polypeptide Triggers Limited Complement Activation and Binds Complement Inhibitor C4b-binding Protein, Which Enhances Fibril Formation ${ }^{*[5]}$
}

Received for publication, March 27, 2011, and in revised form, January 30, 2012 Published, JBC Papers in Press, February 13, 2012, DOI 10.1074/jbc.M111.244285

Jonatan Sjölander ${ }^{\ddagger}$, Gunilla T. Westermark ${ }^{\S}$, Erik Renström", and Anna M. Blom ${ }^{\ddagger 1}$

From the ${ }^{\ddagger}$ Department of Laboratory Medicine, Lund University, Wallenberg Laboratory, Skåne University Hospital, S-20502 Malmö, Sweden, the ${ }^{\S}$ Department of Medical Cell Biology, Uppsala University, S-75123 Uppsala, Sweden, and the

"Department of Clinical Sciences, Islet Pathophysiology, Lund University, Clinical Research Centre, Skåne University Hospital, S-20502 Malmö, Sweden

Islet amyloid polypeptide (IAPP) is synthesized in pancreatic $\boldsymbol{\beta}$-cells and co-secreted with insulin. Aggregation and formation of IAPP-amyloid play a critical role in $\boldsymbol{\beta}$-cell death in type 2 diabetic patients. Because A $\boldsymbol{\beta}$-fibrils in Alzheimer disease activate the complement system, we have here investigated specific interactions between IAPP and complement factors. IAPP fibrils triggered limited activation of complement in vitro, involving both the classical and the alternative pathways. Direct binding assays confirmed that IAPP fibrils interact with globular head domains of complement initiator C1q. Furthermore, IAPP also bound complement inhibitors factor $\mathrm{H}$ and $\mathrm{C} 4 \mathrm{~b}$ binding protein (C4BP). Recombinant $\mathrm{C} 4 \mathrm{BP}$ mutants were used to show that complement control protein (CCP) domains 8 and 2 of the $\alpha$-chain were responsible for the strong, hydrophobic binding of C4BP to IAPP. Immunostaining of pancreatic sections from type 2 diabetic patients revealed the presence of complement factors in the islets and varying degree of co-localization between IAPP fibrils and C1q, C3d, as well as C4BP and factor $\mathrm{H}$ but not membrane attack complex. Furthermore, $\mathrm{C} 4 \mathrm{BP}$ enhanced formation of IAPP fibrils in vitro. We conclude that C4BP binds to IAPP thereby limiting complement activation and may be enhancing formation of IAPP fibrils from cytotoxic oligomers.

Deposition of amyloid is one of the main pathological characteristics in patients with type 2 diabetes (T2D). ${ }^{2}$ These amyloid deposits were first named islet amyloid because of its location inside the islets of Langerhans and later found to consist of the polypeptide hormone, islet amyloid polypeptide (IAPP) (1), which is expressed by the $\beta$-cell and co-secreted together with

\footnotetext{
* This work was supported by Swedish Research Council Grants 2009-68X14928-06-3 and 2010-55X-20326-04-3, the Swedish Foundation for Strategic Research, Swedish Diabetes Foundation and the Foundations of Österlund, Greta and Johan Kock, Family Ernfors, Knut and Alice Wallenberg, and Inga-Britt and Arne Lundberg as well as grants for clinical research from the University Hospital in Malmö and the Region Skåne.

5 This article contains supplemental Fig. S1.

${ }^{1}$ To whom correspondence should be addressed. Tel.: 46-40-338233; Fax: 46-40-337043; E-mail: anna.blom@med.lu.se.

${ }^{2}$ The abbreviations used are: T2D, type 2 diabetes; $A \beta$, amyloid- $\beta$; C4BP, C4bbinding protein; $\mathrm{CCP}$, complement control protein; DMSO, dimethyl sulfoxide; $\mathrm{FH}$, factor $\mathrm{H}$; IAPP, islets amyloid polypeptide; MAC, membrane attack complex; MBL, mannose-binding lectin; NHS, normal human serum; ThT, thioflavin T.
}

insulin $(2,3)$. A reduction in $\beta$-cell number is observed in patients with T2D (4), and the severity of the disease has been suggested to correlate with the amount of IAPP amyloid (5-7). IAPP fibrils are made of several interacting protofilaments. Each protofilament consists of numerous vertical monomers, which are stacked on top of each other, forming an elongated $\beta$-sheet. Formation of amyloid fibrils includes the assembly of smaller intermediates referred to as oligomers (8). Amyloid has been shown to induce apoptosis (9), but the exact cytotoxic conformation remains a matter of debate. Oligomers have the ability to incorporate into membranes and form ion-leaking pores (10), which may be the reason for their cytotoxicity. In this scenario, mature amyloid fibrils appear to be a way to neutralize toxic oligomers safely. However, the existence of IAPP oligomers in vivo is still under debate (11).

The complement system is a pivotal component of innate immunity. Besides its classical functions such as opsonization of pathogens, generation of inflammatory mediators, and cell lysis, its roles in the recognition and removal of dying cells, immune complexes, and misfolded proteins are of significant importance (12). IAPP has been suggested to activate complement (13), and therefore, interactions between complement and IAPP can be of importance for the normal islet physiology, but also for the development of pathologic deposits present in the islets of patients with T2D. The complement cascade is organized in three pathways of which the classical route is triggered by $\mathrm{C} 1$ complex binding to immune complexes causing activation of $\mathrm{C} 4$ and $\mathrm{C} 2$, which together form the classical $\mathrm{C} 3$ convertase (14). The $\mathrm{C} 1$ complex is composed of two proteases $\mathrm{C} 1 \mathrm{~s}$ and $\mathrm{C} 1 \mathrm{r}$ as well as $\mathrm{C} 1 \mathrm{q}$, which recognizes a number of molecules such as immune complexes, $\mathrm{C}$-reactive protein, and misfolded proteins (15). C1q is also present in a free form in tissues and in plasma (10\% of total amount) (16). Spontaneous hydrolysis of $\mathrm{C} 3$ or binding of properdin leads to activation of the alternative pathway (17). The lectin pathway is prompted when mannose-binding lectin (MBL) or ficolins bind carbohydrates present on microbial surfaces. The three pathways converge at the level of C3b, which is followed by formation of the C5 convertase, release of the anaphylatoxin C5a, and assembly of the membrane attack complex (MAC) (18).

If complement was left uncontrolled it would lead to general spontaneous activation with severe tissue damage (12). To prevent this, complement remains under constant control of a 
number of soluble and membrane-bound inhibitors. The main function for $\mathrm{C} 4 \mathrm{~b}$-binding protein $(\mathrm{C} 4 \mathrm{BP})$ is to inhibit the classical and lectin pathways, whereas factor $\mathrm{H}(\mathrm{FH})$ controls the alternative pathway. C4BP and FH circulate in blood and act on the level of $\mathrm{C} 3 / \mathrm{C} 5$ convertases (14), and both inhibitors contain complement control protein (CCP) domains. C4BP is a 570$\mathrm{kDa}$ protein composed of six identical $\alpha$-chains and a unique $\beta$-chain consisting of eight and four CCP domains, respectively (19). The majority of C4BP molecules in the blood circulate in a high affinity complex with protein $\mathrm{S}$ bound to CCP1 of the $\beta$-chain (20). We have previously shown that C4BP interacts with amyloid fibrils formed by amyloid- $\beta(\mathrm{A} \beta)$ in Alzheimer disease and prions $(21,22)$. Under some pathological conditions complement activation can be either excessive or misdirected and contribute to tissue damage (23). The aim of the present study was to elucidate the interactions between complement factors and IAPP fibrils in relation to T2D.

\section{EXPERIMENTAL PROCEDURES}

Proteins-C4BP (24), FH (25), and C1q (26) were purified from human plasma as described whereas MBL was purchased from State Serum Institute, Denmark. C1 complex and properdin were purchased from Complement Technology (Tyler, TX). C1q tail and globular head domains were prepared using partial proteolytic digestion of C1q with pepsin (Worthington Biochemical, Lakewood, NJ) or collagenase from Clostridium histolyticum (Worthington Biochemical), respectively $(27,28)$. Recombinant wild-type (WT) C4BP and mutants lacking individual CCP domains were expressed in eukaryotic cells and purified by affinity chromatography as described (29). The core fragment of C4BP was obtained by limited digestion with chymotrypsin leaving only the $\mathrm{C}$-terminal extension of the $\alpha$-chains together with the CCP8 and a truncated CCP7 (30). Human mature processed full-length IAPP (amino acids 1-37) was purchased from Keck Biotechnology (Yale University, New Haven, CT) and Bachem (Bubendorf, Switzerland). Human IAPP fragment composed of amino acids 20-29 (IAPP(2029)), which is the part of the molecule that contains one of the amyloidogenic sequences of human IAPP as well as nonamyloidogenic rat IAPP, was purchased from Bachem (31). Human IAPP was amidated at $C$ terminus whereas the IAPP $(20-29)$ fragment had a free $\mathrm{C}$ terminus. IAPP peptides and $\mathrm{A} \beta$ (amino acids 1-42; Bachem) were dissolved in DMSO and $0.1 \% \mathrm{NH}_{3}$, respectively. All peptides were aliquoted and stored at $-80^{\circ} \mathrm{C}$, until used except for the aliquot of IAPP used for the thioflavin $\mathrm{T}$ (ThT) experiment, which was stored in DMSO up to several weeks at room temperature. To obtain fibrils, IAPP peptides were diluted with water to a final concentration of $100 \mu \mathrm{g} / \mathrm{ml}$ and $1 \%$ in DMSO and incubated for at least 2 days in glass tubes at room temperature. A $\beta$ formed fibrils already after 1 -h incubation at room temperature in $0.1 \% \mathrm{NH}_{3}$. The presence of fibrils was verified with transmission electron microscopy after negative staining. Furthermore, we also performed several experiments crucial for this study using fibrils formed for more prolonged times (up to weeks) with the same results.

Direct Binding Assays-Microtiter plates (Maxisorp; Nunc, Roskilde, Denmark) were coated overnight at $4{ }^{\circ} \mathrm{C}$ or $2 \mathrm{~h}$ in $37^{\circ} \mathrm{C}$ with $50 \mu \mathrm{l}$ of $1 \% \mathrm{w} / \mathrm{v}$ BSA (Sigma; negative control), 5 $\mu \mathrm{g} / \mathrm{ml}$ A $\beta$ (positive control), full-length human IAPP, IAPP $(20-29)$, or rat IAPP diluted in coating buffer $(75 \mathrm{~mm}$ sodium carbonate buffer, $\mathrm{pH}$ 9.6). For $\mathrm{C} 1 \mathrm{q}$ head/tail binding to IAPP $10 \mu \mathrm{g} / \mathrm{ml} \mathrm{C1q}$ heads and tails were coated to the bottom of the well as well as BSA. All proteins except rat IAPP, C1q, and BSA formed fibrils (32) before coating them onto the plate. The wells were then washed extensively with washing buffer $(50 \mathrm{~mm}$ Tris- $\mathrm{HCl}, 150 \mathrm{~mm} \mathrm{NaCl}, 0.1 \%$ (v/v) Tween 20, $\mathrm{pH}$ 7.5) followed by a 2-h incubation at room temperature with blocking solution, 1\% BSA in PBS or 3\% fish gelatin (Norland Products, Cranbury, NJ) in washing buffer. Purified C1q, C1, MBL, properdin, IAPP FH, and C4BP at concentrations ranging between 0.5 and $50 \mu \mathrm{g} / \mathrm{ml}$ in binding buffer (50 mM HEPES, pH 7.4, $100 \mathrm{~mm}$ $\mathrm{NaCl}, 2 \mathrm{mM} \mathrm{CaCl}_{2}, 50 \mu \mathrm{g} / \mathrm{ml} \mathrm{BSA}$ ) were added to the wells and left to incubate for $1 \mathrm{~h}$ at $37^{\circ} \mathrm{C}$ or $4{ }^{\circ} \mathrm{C}$ overnight. For experiments assessing ionic strength dependence, increasing amounts of $\mathrm{NaCl}$ were added to the binding buffer. Specific polyclonal antibodies, rabbit anti-IAPP 1:4000 (Abcam, Cambridge, UK), rabbit anti-human C1q (Dako, Glostrup, Denmark) diluted 1:6000, goat anti-human FH (Quidel, San Diego, CA) diluted 1:2000, rabbit anti-C4BP (made in house) 3.25 $\mu \mathrm{g} / \mathrm{ml}$ purified IgG fraction, goat anti-MBL (R\&D Systems, Minneapolis, MN) 1:2000 were diluted in blocking solution and incubated for $1 \mathrm{~h}$ at room temperature. This was followed by incubation with swine anti-rabbit IgG (Dako) or rabbit antigoat IgG (Dako) conjugated with horseradish peroxidase (HRP), diluted 1:2000 in a blocking solution. Bound enzyme was visualized using the 1,2-phenylenediamine dihydrochloride (OPD) $/ \mathrm{H}_{2} \mathrm{O}_{2}$ colorimetric substrate (Dako). The reaction was terminated with $0.5 \mathrm{M} \mathrm{H}_{2} \mathrm{SO}_{4}$, and the absorbance was measured at $490 \mathrm{~nm}$ in a plate reader (Varian, Palo Alto CA). The binding assays were repeated with the same result when PBS instead of carbonate buffer was used as coating solution.

Complement Activation Assays-Microtiter plates were incubated overnight at $4{ }^{\circ} \mathrm{C}$ with $50 \mu \mathrm{l}$ of the coating buffer containing $5 \mu \mathrm{g} / \mathrm{ml} \mathrm{A} \beta$, full-length human IAPP, rat IAPP, IAPP (20-29), $2 \mu \mathrm{g} / \mathrm{ml}$ human aggregated IgG (Immuno, Vienna, Austria), or 1\% BSA. The amyloidgenic proteins were coated onto the plates as fibrils. Between each incubation step, the plates were washed four times with washing buffer. The wells were blocked with blocking solution for $1 \mathrm{~h}$ at room temperature. Normal human serum (NHS) was prepared and pooled from blood taken from six healthy donors as approved by the ethical committee of Lund University. Dilutions of NHS in $\mathrm{GVB}^{2+}$ (2.5 mM veronal buffer, $\mathrm{pH}$ 7.3, $150 \mathrm{~mm} \mathrm{NaCl}, 0.1 \%$ gelatin, $1 \mathrm{mM} \mathrm{MgCl}_{2}$ and $0.15 \mathrm{~mm} \mathrm{CaCl} 2$ ) or $\mathrm{Mg}++$ EGTA buffer (2.5 mM Veronal buffer, ph 7.3, $70 \mathrm{~mm} \mathrm{NaCl} 140 \mathrm{~mm}$ glucose, $0.1 \%$ gelatin, $7 \mathrm{~mm} \mathrm{MgCl} 2,10 \mathrm{~mm}$ EGTA) were added to the wells and incubated for $20 \mathrm{~min}$ (for detection of C1q, C3b, and $\mathrm{C} 4 \mathrm{~b}$ ) or $45 \mathrm{~min}(\mathrm{C} 9)$, at $37^{\circ} \mathrm{C}$, followed by incubation with specific rabbit polyclonal antibodies against $\mathrm{C} 1 \mathrm{q}$ (Dako) diluted 1:6000, C3d (Dako) diluted 1:2000, C4b (Dako) diluted 1:2000, FH (Quidel) diluted 1:6000, or goat polyclonal antibodies against C9 (Complement Technology) diluted 1:2000. All antisera were diluted in blocking solution. HRP-conjugated secondary antibodies swine anti-rabbit IgG (Dako) or rabbit antigoat IgG (Dako), were both diluted 1:2000 in blocking solution. 

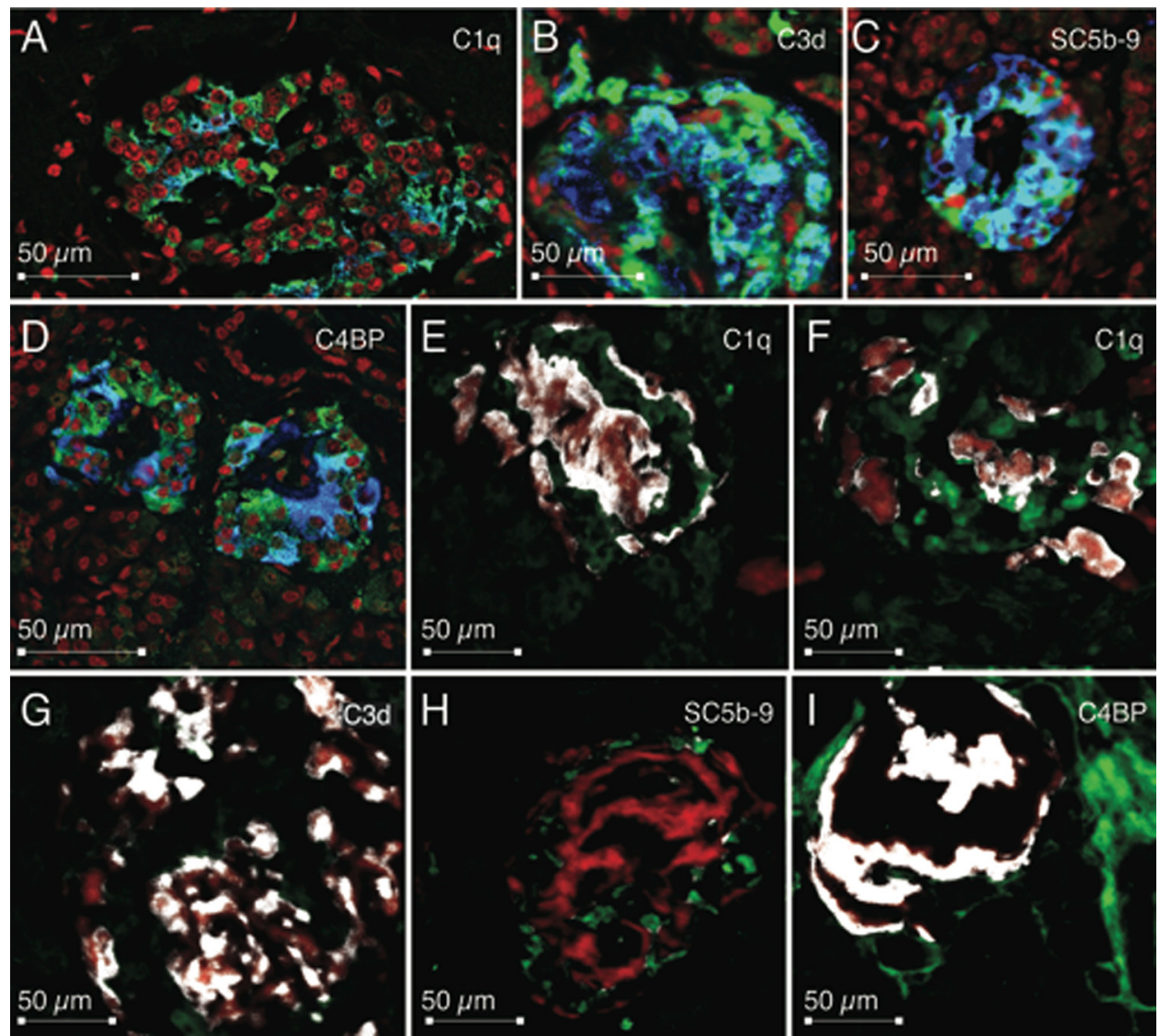

FIGURE 1. Complement components co-localize with IAPP deposits in pancreatic tissue. Formalin-fixed sections of pancreatic tissue from T2D patients were stained with antibodies against IAPP $(A-D)$, C1q $(A)$, C3d $(B), C 5 b-9 ;$ MAC $(C)$, and C4BP $(D)$. The complement factors were visualized using specific antibodies followed by secondary anti-rabbit antibodies conjugated with Alexa Fluor 488 (green), and the IAPP was visualized using secondary anti-mouse antibodies conjugated with Alexa Fluor 647 (blue). Co-localization is indicated by presence of pale blue color. IAPP amyloid was in turn stained with Congo Red $(E-l)$ followed by detection of complement components C1q (E and $F), C 3 \mathrm{~d}(G)$, C5b-9; MAC $(H)$, and C4BP $(I)$ with specific antibodies followed by secondary antibodies labeled with Alexa Fluor 488. Overlapping pixels were visualized as white using the CoLocalizer Pro software. The pictures were taken with a Zeiss LCM 510 confocal microscope. Magnification, $\times 40$.

Bound HRP was measured using the colorimetric assay as described above for the direct binding assay.

Electron Microscopy-An aliquot of $15-\mu \mathrm{l}$ samples of $\mathrm{A} \beta$, full-length IAPP, IAPP $(20-29)$ fibrils, or rat IAPP with the protein concentration of $100 \mu \mathrm{g} / \mathrm{ml}$ or $15 \mu \mathrm{l}$ of sample from ThT experiment after incubation for various time points and containing IAPP alone or IAPP with highest concentration of C4BP tested were placed on Formvar-coated copper grids (Link, Nordic Analytical, Lidingö, Sweden) and incubated for $30 \mathrm{~s}$. The peptide solution was then replaced by $2 \%$ uranyl acetate (Link) in $50 \%$ ethanol. The fibrils were studied at $100 \mathrm{kV}$ in a Jeol 1230 electron microscope (Jeol, Akishima, Japan). Electron micrographs were taken with a Gatan multiscan camera model 791 using Gatan digital software version 3.6.4 (Gatan, Pleasanton, CA).

Fluorescence Microscopy - sections of pancreas from patients with T2D were used to visualize complement factors in the islets. The tissue material has been anonymized, and the ethical board at Uppsala University has approved its use in research. Formalin-fixed paraffin-embedded sections were mounted on glass slides and deparaffinized in xylene for $2 \times 10 \mathrm{~min}$, rehydrated with decreasing percentage of ethanol and distilled water. Antigen retrieval was performed to expose epitopes by incubation in $0.01 \mathrm{M}$ sodium-citrate buffer, $\mathrm{pH} 6.0$, at $99^{\circ} \mathrm{C}$ for
20 min for the exception of C4BP staining where the antigen recovery heating only lasted $1 \mathrm{~min}$. All sections were rinsed three times with $0.05 \mathrm{M}$ Tris with $0.15 \mathrm{M} \mathrm{NaCl}, \mathrm{pH} 7.4$ (TBS) and incubated with primary antibodies overnight at $4{ }^{\circ} \mathrm{C}$. The following antibodies were included: goat anti-FH (Quidel) diluted 1:250, affinity-purified rabbit anti-C4BP $(13 \mu \mathrm{g} / \mathrm{ml})$, rabbit anti-C1q (Dako) diluted 1:125, rabbit anti-C3d (Dako) diluted 1:250, or rabbit anti-SC5b-9 (Complement Technology) diluted 1:250. The formalin-fixed sections were also incubated with a mouse anti-IAPP antibody (Abcam) diluted 1:100. The antibody binds amino acids 7-17 of processed mature human IAPP thus recognizing IAPP in intracellular insulin granules, intracellular amyloid, and extracellular islet amyloid. After washing in TBS the sections were incubated for $3 \mathrm{~h}$ at room temperature with Alexa Fluor 488-labeled secondary antibodies (Molecular Probes, Eugene OR) diluted 1:1000 in TBS. IAPP reactivity was visualized with Alexa Fluor 647 (Molecular Probes) diluted 1:1000 in TBS for $3 \mathrm{~h}$ at room temperature. Some of the sections were also stained for amyloid with Congo Red (Sigma) as described (33). The paraffin sections were analyzed on a Zeiss LCM 510 confocal microscope. All images are representative of at least three independent staining experiments. Co-localization was calculated using CoLocalizer Pro (CoLocalization Research 
TABLE 1

Co-localization between IAPP and complement components, using Manders correlation coefficient, $R$

$R$ can vary from 0 to 1 , and value of 0.5 implies that $50 \%$ of both channels co-localize. Congo Red staining detects IAPP amyloid, and the antibody recognizes all intracellular and extracellular forms of IAPP.

\begin{tabular}{lcc}
\hline Complement protein & Congo Red staining & IAPP antibody \\
\hline & $R$ value & $R$ value \\
C1q & $0.33 \pm 0.13$ & $0.66 \pm 0.13$ \\
C3d & $0.71 \pm 0.09$ & $0.64 \pm 0.04$ \\
SC5b-9 (MAC) & $0.15 \pm 0.14$ & $0.77 \pm 0.04$ \\
FH & $0.48 \pm 0.06$ & $0.65 \pm 0.17$ \\
C4BP & $0.77 \pm 0.02$ & $0.69 \pm 0.09$ \\
\hline
\end{tabular}

Software), and three representative images were acquired independently for each staining (34).

Thioflavin T Assay-A kinetic study of amyloid fibril formation was carried out in black 96-well plates (Nunc). Full-length IAPP (Keck) was diluted from a stock of $20 \mathrm{mg} / \mathrm{ml}$ IAPP in DMSO (kept at room temperature) to a final concentration of $17 \mu \mathrm{g} / \mathrm{ml}$ in $50 \mathrm{~mm}$ glycine, $25 \mathrm{~mm}$ sodium phosphate buffer, $\mathrm{pH}$ 7.0 , yielding a final concentration of $0.3 \%$ DMSO. C4BP dialyzed against the same buffer or BSA $(10 \mathrm{mg} / \mathrm{ml}$, negative control) were also added to the wells to final concentrations ranging from 0 to $300 \mu \mathrm{g} / \mathrm{ml}$ followed by $10 \mu \mathrm{M}$ ThT (Sigma). Excitation was set to $442 \mathrm{~nm}$ and emission to $482 \mathrm{~nm}$, and the fluorescence was measured every $10 \mathrm{~min}$ for $16 \mathrm{~h}$ using an Infinity 200 microplate reader equipped with a Quad4 monochromator (Tecan, Männedorf, Switzerland).

Statistical Analysis-Student's $t$ test for unpaired samples, two-way ANOVA with Bonferroni and one-way ANOVA with Tukey's multiple comparison test were used to evaluate statistical significance of differences between groups (GraphPad Software); *, $p<0.05$; ${ }^{* *}, p<0.01$; ${ }^{* * * *}, p<0.001$.

\section{RESULTS}

Complement Factors C1q, C3d, C5b-9, and Complement Inhibitors C4BP and FH Co-localize to Various Extents with IAPP and IAPP Fibrils in Human Pancreatic Tissue-Because human IAPP was reported to trigger complement activation via the classical pathway (13), amyloid-containing pancreatic sections from patients with T2D were stained for complement components. The co-localization was quantified using CoLocalizer Pro software. Confocal microscopy analysis revealed colocalization of C1q (Fig. 1A), C3d (Fig. 1B), and C5b-9 complexes (component of MAC; Fig. $1 C$ ) as well as inhibitors C4BP (Fig. $1 D$ ) and FH (supplemental Fig. S1D) with IAPP visualized with monoclonal antibody detecting all forms of intra- and extracellular IAPP (Fig. 1, $A-D$ ). Amyloid detected with Congo Red staining was also labeled to various extents by $\mathrm{C} 1 \mathrm{q}, \mathrm{C} 3 \mathrm{~d}$, C5b-9, C4BP (Fig. 1, E-I), and FH (supplemental Fig. S1E)specific antibodies, and merged overlapping pixels where visualized as white using the CoLocalizer Pro software. Quantitative analyses of co-localization yielded overlap coefficients according to Manders et al. (34) ( $R$; Table 1$). R$ indicates an actual overlap of the two signals and is considered to represent true co-localization. All studied complement proteins showed significant co-localization with IAPP, but only C3d and C4BP co-localized to a high degree with mature fibrils. This indicates that $\mathrm{FH}$ and $\mathrm{MAC}$ are present in the islets but not exclusively
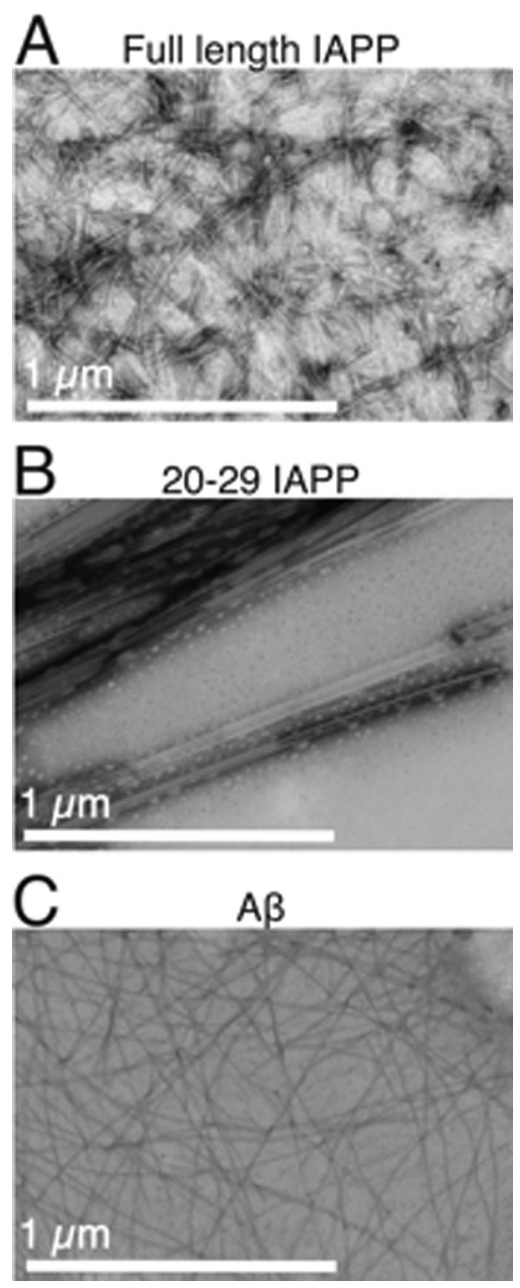

FIGURE 2. Visualization of IAPP fibrils formed in vitro. Panels show successful fibril formation for full-length IAPP $(A), \operatorname{IAPP}(20-29)(B)$, and $A \beta(C)$ visualized by electron microscopy. The presented images are representative of three separate experiments.

bound to the mature IAPP fibrils. Results obtained for C1q varied between deposits within the same pancreatic section, some islets showing almost no co-localization with IAPP fibrils $(r=0.2$, Fig. $1 F)$ whereas others had a high degree of such co-localization $(r=0.72$, Fig. $1 E)$. The studied complement proteins were largely limited to islets and blood vessels, with the exception of $\mathrm{FH}$, and that were also weakly detectable in the exocrine pancreas.

A $\beta$, Full-length Human IAPP, and IAPP(20-29) Form Fibrils in Contrast to Rat IAPP_Electron microscopy was used to ascertain that the IAPP variants used in this study form fibrils as described previously (31). As previously reported, rat IAPP lacked entirely the ability to form fibrils (data not shown). By contrast, $\mathrm{A} \beta$ formed extensive fibrils under the experimental conditions used (Fig. 2C). Full-length IAPP formed fibrils very similar to $\mathrm{A} \beta$ (Fig. $2 A$ ) whereas $\operatorname{IAPP}(20-29)$ formed thicker, well structured fibrils (Fig. 2B).

IAPP Binds C1q and Activates Weakly Classical and Alternative Pathways of Complement in Vitro-The histological findings indicated deposition of C3d co-localized with islet amyloid. To investigate the capacity of IAPP to bind C1q and to activate the classical complement cascade in vitro we coated 

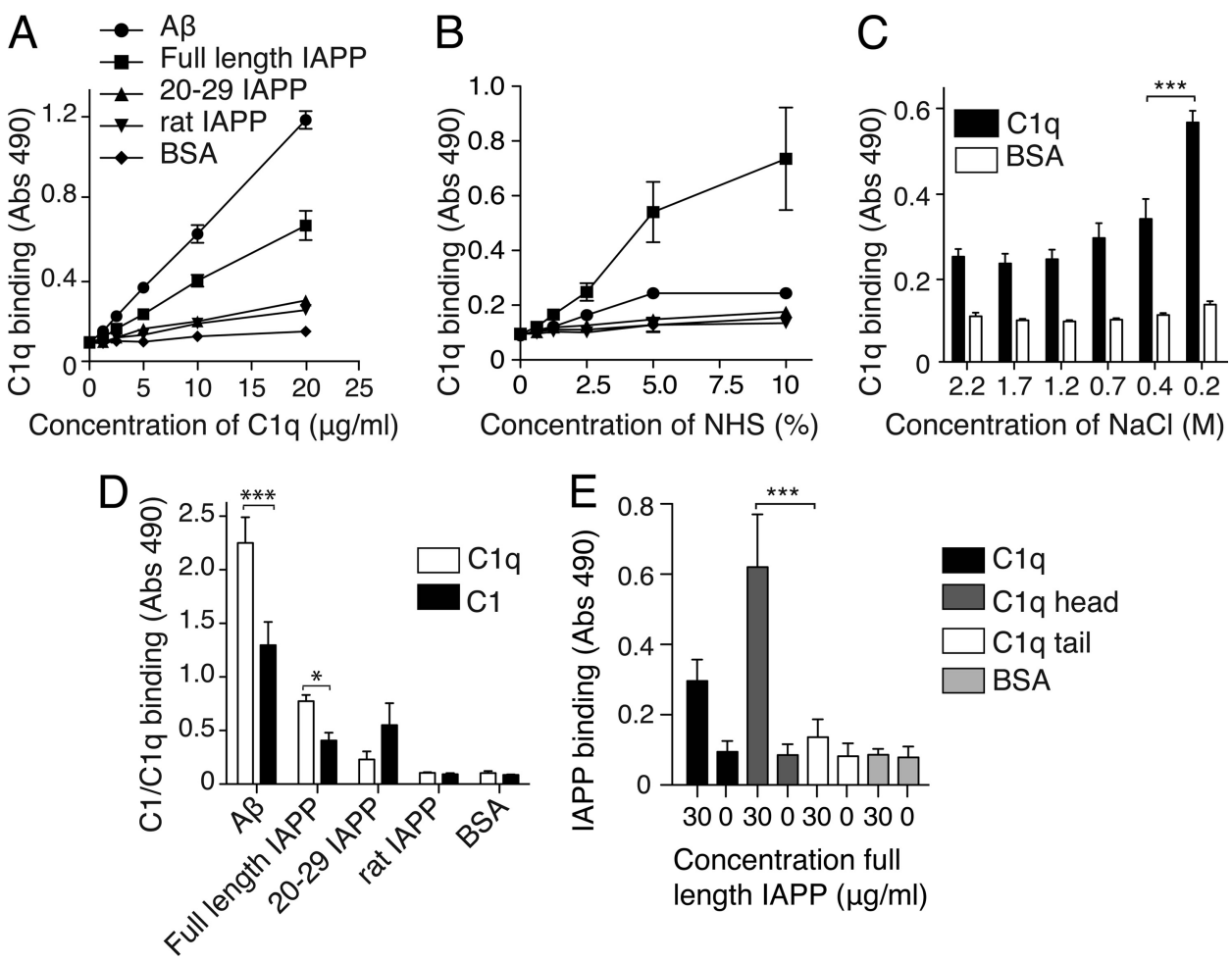

FIGURE 3. IAPP binds head domains of C1q. $A$ and $B$, IAPP variants were coated on the microtiter plate, and in the fluid phase purified C1q $(A)$ or NHS ( $B$ ) was added in increasing concentrations followed by detection of bound $\mathrm{C} 1 \mathrm{q}$ with antibodies. Purified $\mathrm{C} 1 \mathrm{q}$ bound to IAPP in a concentration-dependent manner with full-length IAPP showing strongest binding $(A)$. C $1 \mathrm{q} / \mathrm{C} 1$ from NHS bound only to full-length IAPP $(B)$. C, binding between purified C1q (10 $\mu \mathrm{g} / \mathrm{ml})$ and full-length IAPP is dependent on ionic interactions as the interaction was inhibited with increasing $\mathrm{NaCl}$ concentrations added to the binding buffer. $D$, when purified C1q and C1 complex (both at $50 \mu \mathrm{g} / \mathrm{ml}$ ) were incubated with immobilized IAPP, C1q showed stronger binding than C1. E, immobilized C1q and C1q head and C1q tail fragments ( $10 \mu \mathrm{g} / \mathrm{ml}$ ) were incubated with $30 \mu \mathrm{g} / \mathrm{ml} \mathrm{IAPP}$, and only purified C1q and C1q heads showed significant binding detected by polyclonal anti IAPP antibody. In $A-D, A \beta$ was used as a positive control. In $A-E, B S A$ was used as negative control. The results are given as means \pm S.D. (error bars) for at least three independent experiments. ANOVA analyses were used for all statistical evaluations. $A$, all IAPP variants and A $\beta$, at a concentration of 20 $\mu \mathrm{g} / \mathrm{ml}$, showed a statistically significant binding compared with BSA. $B$, full-length IAPP was the only protein showing a statistically significant difference in binding compared with BSA at 2.5,5.0, and $10.0 \%$ serum concentrations. $C$, we noted statistically significant differences for all NaCl concentrations ( ${ }^{* * *}, p<$ $0.001)$ compared with the physiological $\mathrm{NaCl}$ concentration $(0.15 \mathrm{M})$. $D$, statistically significant differences were found for $\mathrm{A} \beta(* * *, p<0.001)$ and full-length IAPP $(*, p<0.05)$ compared with BSA in regards to binding of both $\mathrm{C} 1$ and $\mathrm{C} 1 \mathrm{q}$.

microtiter plates with different variants of IAPP and $\mathrm{A} \beta$ (positive control) (18), followed by incubation with purified C1q. C1q bound to both $\mathrm{A} \beta$ as well as full-length IAPP and weakly to rat IAPP and human (20-29) IAPP (Fig. 3A). Furthermore, there was binding of $\mathrm{C} 1 \mathrm{q} / \mathrm{C} 1$ from NHS to full-length IAPP and weak interaction with $\mathrm{A} \beta$ (Fig. $3 B$ ). The interaction between purified $\mathrm{C} 1 \mathrm{q}$ and full-length IAPP was based on ionic interactions and decreased with increasing ionic strength of a binding buffer (Fig. 3C). Next, a binding assay using purified components showed that both free $\mathrm{C} 1 \mathrm{q}$ and the $\mathrm{C} 1$ complex bound IAPP immobilized on microtiter plate (Fig. 3E). Furthermore, IAPP bound head domains but not tail regions of C1q (Fig. 3F). No binding of MBL or ficolins-1 and -3 from NHS to immobilized IAPP could be detected (data not shown).

Binding of C1q from NHS to IAPP was rather weak, and we therefore used deposition assays detecting consecutive components of the complement cascade to determine the degree of IAPP-mediated complement activation. All IAPP variants as well as $\mathrm{A} \beta$ triggered weak but statistically significant $\mathrm{C} 4 \mathrm{~b}$ deposition (Fig. 4A). In the classical pathway, deposition of C3b (Fig. $4 B$ ) as well as the MAC/C9 molecules (Fig. 4C) was detectable, albeit even weaker than that observed for C4b. Furthermore, IAPP caused more C3b deposition than C9 when conditions allowing only activation of the alternative pathway were used (Fig. 4, $D$ and $E$ ). The observed low degree of activation of the alternative pathway was not due to direct interaction between properdin and IAPP (data not shown).

C4BP Binds Strongly to IAPP in Hydrophobic Manner-Deposition of C3b and C9 triggered by IAPP was weaker than that of $\mathrm{C} 4 \mathrm{~b}$ in the classical pathway. This taken together with the fact that C4BP binds other types of amyloid (22) prompted us to test whether it also binds IAPP. Indeed, purified C4BP bound strongly to full-length human IAPP and more weakly to rat IAPP and human IAPP (20-29) (Fig. 5A). A $\beta$ and BSA were used as positive and negative controls, respectively. C4BP from NHS bound efficiently to all forms of IAPP (Fig. $5 B$ ). The binding was mainly based on hydrophobic interactions because the interaction was enhanced at higher $\mathrm{NaCl}$ concentrations (Fig. 5C). No competition for binding to IAPP was found between C4BP and C1q or between C4BP and FH (data not shown).

IAPP Interacts with CCP 2 and CCP8 of C4BP $\alpha$-Chain-To examine which part of the C4BP-PS complex that bound IAPP, we used a direct binding assay with a number of C4BP mutants and fragments (Fig. 6A). Recombinant C4BP composed of only $6 \alpha$-chains and lacking protein $S$ and the $\beta$-chain (25) bound to IAPP with efficiency comparable with C4BP purified from plasma (Fig. 6B), implying that the binding site of IAPP was localized in the $\alpha$-chain of C4BP. The binding site was then 


\section{Classical Pathway}
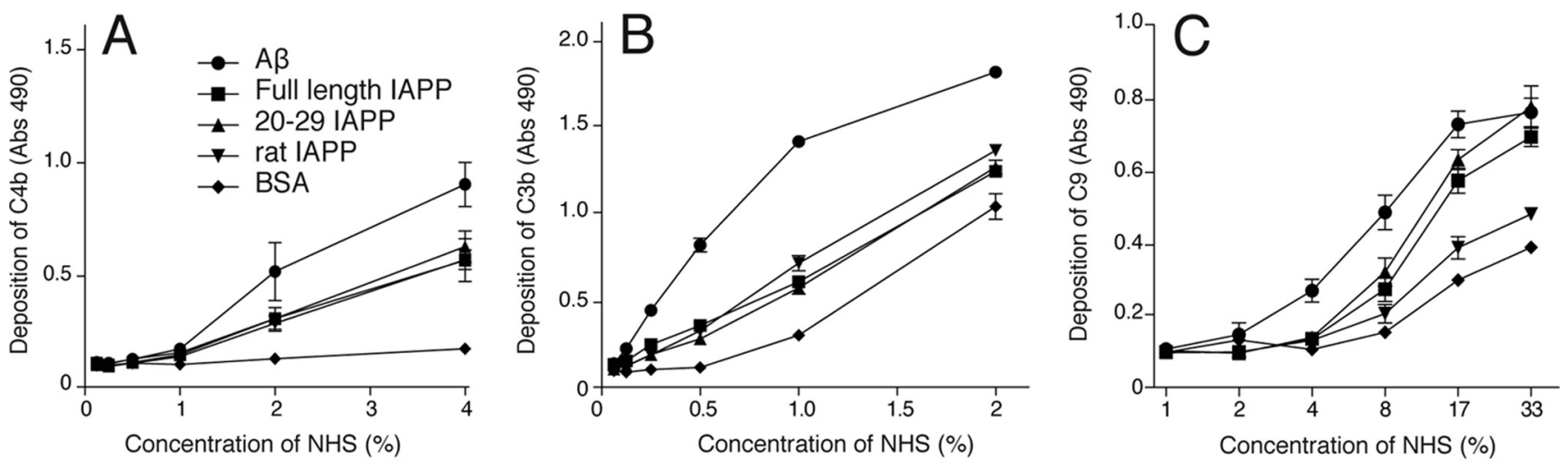

Alternative Pathway
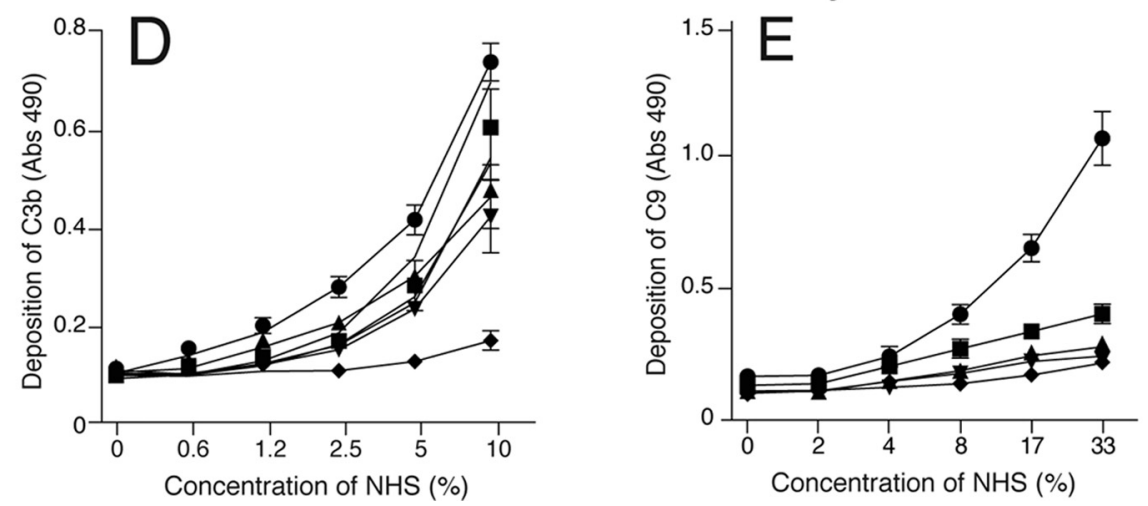

FIGURE 4. IAPP variants trigger limited complement activation via the classical and the alternative pathways. IAPP variants were coated on microtiter plates and incubated with increasing concentrations of NHS diluted in $\mathrm{GVB}^{2+}$ (classical pathway) or Mg-EGTA (alternative pathway). A $\beta$ and BSA were used as a positive and a negative control, respectively. Following complement activation, depositions of $C 4 \mathrm{~b}(A), \mathrm{C} 3 \mathrm{~b}(B$ and $D)$, and $C 9(C$ and $E)$ were detected with specific antibodies. All IAPP variants triggered limited complement activation both through the classical $(A-C)$ and the alternative pathway $(D$ and $E)$ most apparent at the level of $\mathrm{C} 4 \mathrm{~b}$. The results are shown as means \pm S.D. (error bars) from three independent experiments. ANOVAs were used for the statistical evaluations. A, statistically significant differences for A $\beta$, full-length IAPP, IAPP(20-29), and rat IAPP compared with BSA at both 2 and $4 \%$ serum. $B$, statistically significant differences for $A \beta$ and all IAPP variants compared with BSA at both 1 and $2 \%$ serum. $C$, statistical significant differences for $A \beta$, full-length IAPP, IAPP(20-29), and rat IAPP compared with BSA at both 16.5 and $33 \%$ serum. $D$, statistically significant differences for A $\beta$ and all IAPP variants compared with BSA at both 5 and $10 \%$ serum. $E$, statistical significant differences for both $A \beta$ and full-length IAPP at both 16.75 and $33 \%$ serum.

localized to CCP2 and CCP8 in the C4BP $\alpha$-chain in assays employing C4BP mutants lacking one CCP domain each. This was further confirmed by the observation that the core fragment of C4BP containing a fragment of CCP7, the whole CCP8 and C-terminal polymerization region also bound IAPP (Fig. $6 B)$.

C4BP Enhances Fibril Formation-To evaluate further the role of C4BP in IAPP amyloidosis we measured the kinetics of fibril formation in the presence of C4BP. To this end we used ThT that undergoes a detectable shift in fluorescence upon interaction with fibrils but not monomers or oligomers of IAPP. Under the conditions used, 75,150 , and $300 \mu \mathrm{g} / \mathrm{ml} \mathrm{C4BP}$ yielded significantly higher end point fluorescence (Fig. $7 A$ ). Furthermore, addition of $300 \mu \mathrm{g} / \mathrm{ml} \mathrm{C4BP}$ resulted in a significantly shorter lag phase. Fitting the data to a sigmoidal doseresponse curve and estimating the $T_{50}$ (time to $50 \%$ completion) values between 0 and $900 \mathrm{~min}$ validated the above observations. The concentration of $300 \mu \mathrm{g} / \mathrm{ml} \mathrm{C4BP}$ gave a lower $T_{50}$ value (217.0-259.2 min within a 95\% confidence interval) compared with IAPP alone (291.9-329 min within a $95 \%$ confidence interval). Fig. $7 B$ shows the dose-dependent effect of C4BP on fibril formation at $400 \mathrm{~min}$ (Fig. 7B). C4BP alone (in the absence of IAPP) did not affect the fluorescence intensity of ThT (data not shown). BSA showed no enhancement of fibril formation (Fig. $7 B$ ), nor did several other plasma proteins tested (data not shown). EM analysis of sample aliquots of ThT experiment verified the effect of C4BP. In the sample containing IAPP and $300 \mu \mathrm{g} / \mathrm{ml} \mathrm{C4BP}$ there were easily detectable fibrils (Fig. $7 \mathrm{C}$ ) at much earlier time point than in the sample containing IAPP alone. Mature fibrils formed in the presence of C4BP did not differ in morphology from those formed by IAPP alone when analyzed after 960 min.

FH Binds to IAPP-The fact that the deposition of C9 triggered by IAPP was lower than that of C3b in the alternative pathway (Fig. 4, $D$ and $E$ ) indicated that IAPP may interact with FH. Indeed, purified FH bound weakly to all forms of IAPP and strongly to $\mathrm{A} \beta$ (supplemental Fig. S1A). FH from NHS bound weakly to all forms of IAPP and A $\beta$ (supplemental Fig. S1B). The interaction between FH and IAPP was largely independent of ionic interactions because it was not decreased at higher $\mathrm{NaCl}$ concentrations (supplemental Fig. S1C). The small increase in binding observed at $2 \mathrm{M} \mathrm{NaCl}$ indicated a hydrophobic component in the interaction. 

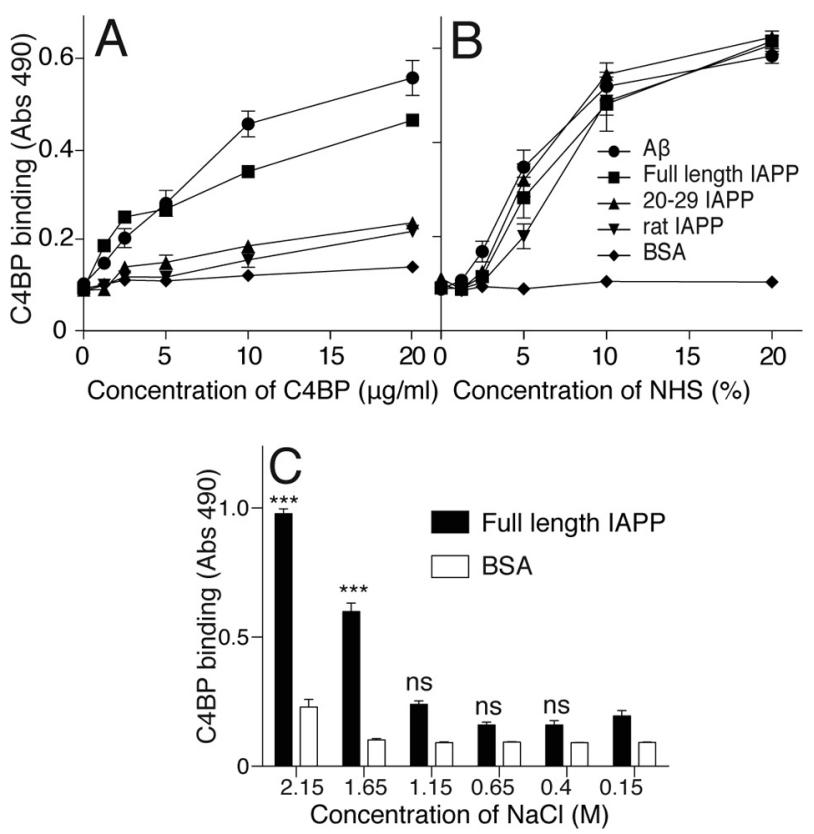

FIGURE 5. IAPP binds complement inhibitor C4BP. Increasing concentrations of purified C4BP $(A)$ or NHS $(B)$ were incubated with immobilized IAPP variants as well as $A \beta$ and $B S A$, and the binding was detected with specific antibodies. Purified C4BP bound mainly full-length IAPP whereas C4BP from serum interacted with all IAPP forms with equal apparent affinity. The interaction between purified C4BP $(10 \mu \mathrm{g} / \mathrm{ml})$ and full-length IAPP increased severalfold at high $\mathrm{NaCl}$ concentrations, implying that it is based on hydrophobic interactions. The results are presented as means \pm S.D. (error bars) for three independent experiments. ANOVAs were used for all statistical evaluations. $A$, statistically significant differences for $A \beta$, full-length IAPP, IAPP(20-29), and rat IAPP compared with BSA at $20 \mu \mathrm{g} / \mathrm{ml}$ C4BP. $B, A \beta$, full-length IAPP, IAPP(20-29), and rat IAPP exhibit statistically significant differences in binding compared with BSA at 10 and $20 \%$ serum. C, statistically significant differences for $1.65 \mathrm{M}$ and $2.15 \mathrm{M} \mathrm{NaCl}$ compared with the physiological $\mathrm{NaCl}$ concentration $\left.(0.15 \mathrm{M}) ;{ }^{* * * *}, p<0.001\right)$.

\section{DISCUSSION}

T2D is associated with chronic low grade inflammation (35) and an up-regulation of complement factors (36), but the exact triggering mechanism remains unknown. A previous study indicated a certain complement activating potential of IAPP (13) produced and secreted by the pancreatic $\beta$-cell. This observation suggested a novel link between T2D and complement, which is particularly important now when pharmacological complement inhibitors are emerging in clinical trials (37).

The aim of the present study was to investigate interactions between complement factors and IAPP fibrils in relation to T2D. Complement activation could contribute to death of $\beta$-cells due to assembly of MAC and in addition, fuel local inflammation by releasing anaphylatoxins. The findings from both the in vitro deposition assays measuring $\mathrm{C} 1 \mathrm{q}, \mathrm{C} 4 \mathrm{~b}, \mathrm{C} 3 \mathrm{~d}$, and $\mathrm{C} 9$ as well as the tissue stainings (Fig. $1, A-H$ ) confirmed such a limited activation of the complement system by IAPP. The peptide was capable of weakly triggering the alternative pathway in vitro, which was not attributable to binding of properdin (data not shown). It is reasonable to presume that the observed IAPP-induced activation of the classical/lectin complement pathway was initiated by the binding of $\mathrm{C} 1$ to IAPP, as shown by the in vitro binding assay. Although we could not detect any interaction with MBL or ficolins from serum we found that the binding of purified C1q to IAPP was signifi-
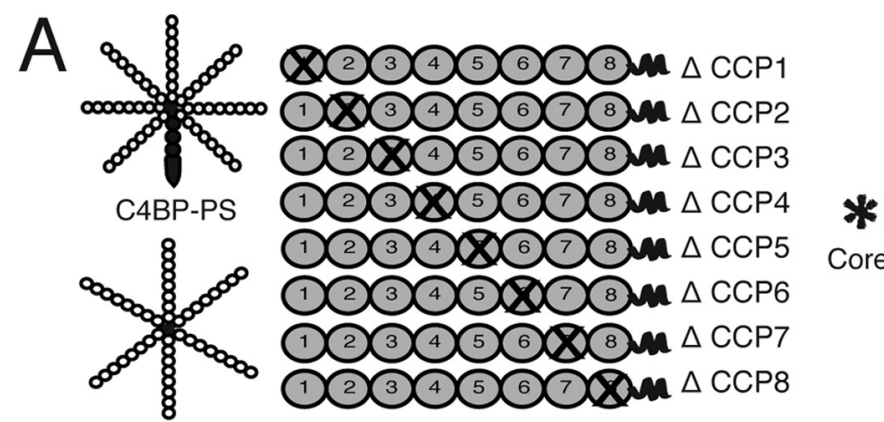

Recombinant C4BP

Recombinant mutants

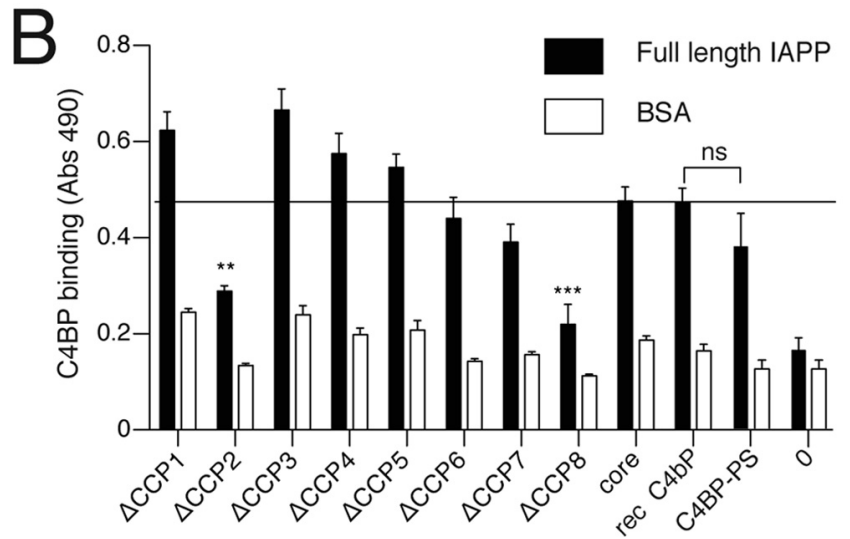

FIGURE 6. C4BP domains CCP2 and CCP8 of $\alpha$-chain bind IAPP. A, schematic represents different $C 4 B P$ variants used in this study. The predominant form of C4BP found in plasma is composed of $7 \alpha$-chains and one $\beta$-chain with bound protein $\mathrm{S}$. The recombinant $\mathrm{C} 4 \mathrm{BP}$ lacks both $\beta$-chain and protein $\mathrm{S}$ but retains capacity to inhibit complement. Core was prepared by digestion with chymotrypsin and contains the C-terminal polymerization region of C4BP with CCP8 and part of CCP7 domain. The panel also outlines the recombinant deletion mutants of C4BP that lack indicated CCP domains. B, all C4BP variants were incubated at $10 \mu \mathrm{g} / \mathrm{ml}$ with immobilized full-length IAPP, and the binding was detected with polyclonal antibody. BSA was used as a negative control. The recombinant WT C4BP bound well to IAPP, indicating that the binding site is localized to the $\alpha$-chain. CCP2 and CCP 8 were required for the interaction, and the presence of binding site in the $C$ terminus of C4BP was confirmed by binding of the core to IAPP. The results are presented as means \pm S.D. (error bars) for three independent experiments. $B$ shows statistically significant differences for the deletion mutants CCP2 $(* *, p<0.01)$ and CCP8 (***, $p<0.001)$ compared with WT C4BP using ANOVA; ns, not significant.

cant. The binding of $\mathrm{C} 1 \mathrm{q} / \mathrm{C} 1$ from NHS to IAPP was rather low and observed only for full-length IAPP, which is likely to be explained by the fact that concentration of free $\mathrm{C} 1 \mathrm{q}$ is low in NHS whereas the purified C1 complex only bound weakly to full-length IAPP. IAPP bound globular head domains and not $\mathrm{C} 1 \mathrm{q}$ tails, which is characteristic of ligands activating $\mathrm{C} 1$ complex (15). Thus, C1q appears to interact with a number of distinct amyloid structures such as $\mathrm{A} \beta$-fibrils in Alzheimer disease with implications for complement activation and macrophage phagocytosis (38). Also amyloid plaques in Down syndrome (39), familial British dementia, and familial Danish dementia (40) bind C1q to form stable complexes. Furthermore, amyloid-forming prion proteins also bind and activate C1q (21).

One reason for the observed low level of MAC deposition is the interactions of IAPP with complement inhibitors such as $\mathrm{C} 4 \mathrm{BP}$ and $\mathrm{FH}$. Such a phenomenon, i.e. limitation of complement activation by $\mathrm{C} 4 \mathrm{BP}$ and $\mathrm{FH}$ on endogenous ligands such 

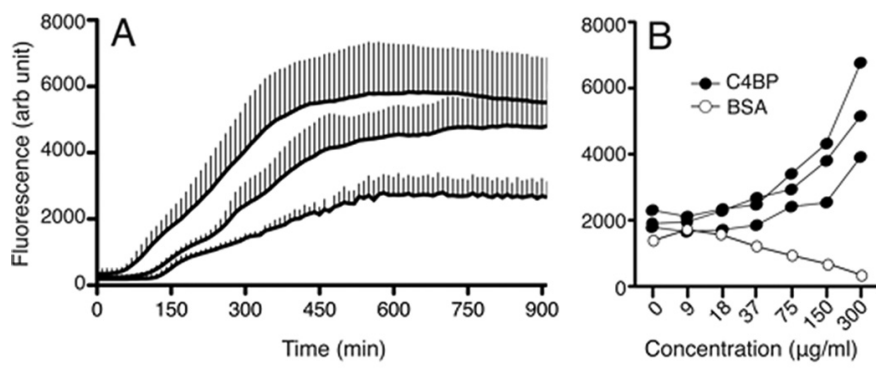

C

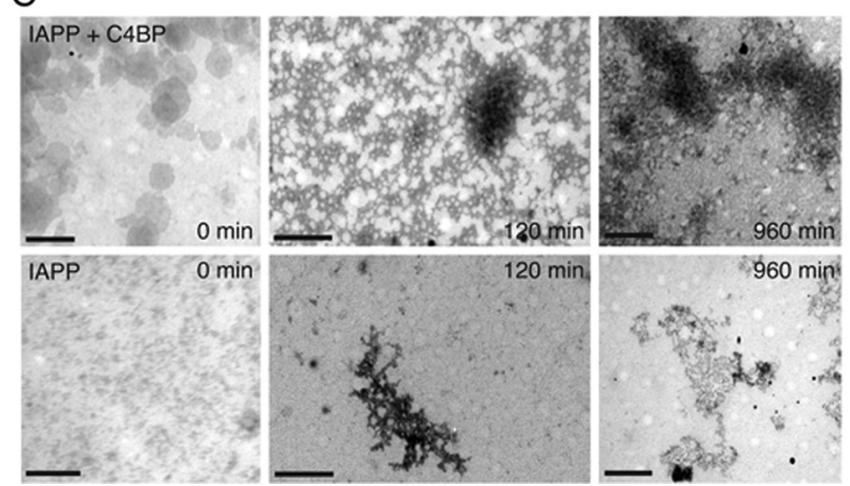

FIGURE 7. C4BP-mediated modulation of the kinetics of IAPP aggregation. $A$, kinetics of IAPP fibril formation in the presence of ThT and C4BP (concentrations ranging from 18 to $300 \mu \mathrm{g} / \mathrm{ml}$ with curves obtained for only 150 and $300 \mu \mathrm{g} / \mathrm{ml}$ of (4BP shown in the figure for clarity). The results are presented as means \pm S.D. for three independent experiments. There was a significant increase of the amount of fibril formation in the presence of 75 (*, $p<0.05$, data not shown), $150(* *, p<0.001)$, and $300 \mu \mathrm{g} / \mathrm{ml} \mathrm{C4BP}(* * *, p<$ $0.0001)$ compared with IAPP alone estimated using two-way ANOVA with Bonferroni post test at the end point. Addition of $38 \mu \mathrm{g} / \mathrm{ml}$ or less C4BP did not significantly alter the fibril formation. $B$, effects of different C4BP concentrations in the individual experiments at fixed time point of $400 \mathrm{~min}$. BSA, the negative control did not enhance fibril formation at any concentration tested. C, upper, EM pictures depicting IAPP fibril formation in the presence of 300 $\mu \mathrm{g} / \mathrm{ml} \mathrm{C4BP}$ and analyzed at time points 0,120 , and $960 \mathrm{~min}$. C, lower, EM pictures from IAPP fibril formation at the same time points. Extensive amounts of small fibrillar aggregates were abundantly detected on all analyzed grids in the presence of C4BP already at time point $120 \mathrm{~min}$, and aggregate size increased with time. In samples from aggregating IAPP alone there were only few aggregates detected, examples of such aggregates detected at 120 and $960 \mathrm{~min}$ are shown. Scale bars, $200 \mathrm{~nm}$.

as apoptotic cells, C-reactive protein, or misfolded proteins, has been observed previously (21). FH showed statistically significant but a very weak binding to IAPP whereas we could demonstrate a strong binding of C4BP to IAPP in vitro, both in purified form and from NHS. Using different recombinant deletion mutants of C4BP, this hydrophobic interaction could be mapped to the CCP2 and CCP8 domains. This is similar to what we observed previously for the $\mathrm{A} \beta$-C4BP interaction, which is hydrophobic and dependent on CCP7-8 (22). Thus, it appears that the binding to amyloid may be a general property of C4BP and not specific for a particular type of amyloid. Importantly, C4BP bound to amyloid can be expected to inhibit complement because the binding sites for $\mathrm{C} 4 \mathrm{~b}$ and $\mathrm{C} 3 \mathrm{~b}$ required for complement inhibitory activity of $\mathrm{C} 4 \mathrm{BP}$ are localized to CCP1-4 (29). Indeed, we have observed previously that this was the case for $\mathrm{A} \beta(22)$ and amyloid fibrils of prion protein (21). Importantly, C4BP is a polymer of seven identical $\alpha$-chains and therefore contains multiple interaction sites for all ligands that bind $\alpha$-chains.

To investigate the physiological relevance of the detected interactions between complement and IAPP, we examined deposition of complement factors and inhibitors in pancreatic tissue from T2D patients using immunostaining. A high degree of co-localization between C4BP and IAPP was observed in pancreas both upon staining of IAPP with antibodies and Congo Red confirming the in vitro findings obtained using purified proteins and whole serum. However, C4BP co-localized to a larger degree with IAPP amyloid detected with Congo Red than with total intra- and extracellular IAPP stained with antibody (Fig. 1, $D$ and $H$ ), indicating that C4BP may preferentially be bound to IAPP fibrils. We also observed significant deposits of C1q, C3d, C5b-9 (MAC), and FH in the pancreatic islets; however, only C3d was found to co-localize strongly with the mature Congo Red-stained IAPP fibrils. MAC showed virtually no co-localization with IAPP fibrils, indicating that C4BP and FH efficiently down-regulate IAPP-fibril mediated complement activation in vivo. Interestingly, a high degree of co-localization was found between MAC and IAPP detected with antibodies, implying that MAC components may be expressed by $\beta$-cells and co-localize intracellularly with nonfibrillar IAPP. $\mathrm{FH}$ showed most widely distributed staining including areas outside pancreatic islets, but it was found to co-localize to $48 \%$ with IAPP fibrils. Results obtained for C1q varied between deposits within the same pancreatic section with regards to degree of co-localization with IAPP fibrils. The reason for such diversity is unknown and requires further investigation with larger clinical material. In contrast to C1q, all amyloid-containing islets stained for C3d, indicating that in addition to activation of the classical pathway there is also deposition of C3d via the alternative pathway in vivo. We have not performed tissue staining for initiators of the lectin pathway such as MBL and ficolins, but no binding of these molecules to IAPP could be detected in ELISAs, indicating that the lectin pathway is not triggered by IAPP amyloid. Interestingly, in vitro binding and deposition assays suggest that in addition to IAPP fibrils also nonfibrillar IAPP as the one found in rat can trigger some degree of complement activation.

Amyloid deposits can be very extensive and replace all the $\beta$-cells in an islet without overt signs of inflammation (41). This might at least in part be explained by the significant binding of the complement inhibitors C4BP and FH to the IAPP fibrils thus attenuating complement activation and inflammation. C4BP enhanced fibril formation by facilitating faster aggregation of IAPP. We hypothesize that by doing so C4BP minimizes the presence of cytotoxic oligomers of IAPP or perhaps in parallel the binding of C4BP to the IAPP oligomers could directly block their cytotoxic effect. We have found previously that C4BP bound equally well to mature fibrils and oligomers of prion protein (21). Certainly, one cannot exclude that the binding of C4BP to IAPP has additional physiological functions. It is possible that complexes between C4BP and IAPP amyloid are already formed inside the $\beta$-cells. Expression databases report that $\mathrm{C} 4 \mathrm{BP}$ is expressed mainly in liver hepatocytes and then in the lung but also in pancreatic $\beta$-cells (42).

In conclusion, we propose that IAPP deposited in pancreas in the form of amyloid causes limited complement activation in vivo. These results are supported by in vitro findings. Furthermore, complement inhibitor C4BP is bound in large quantities to IAPP in pancreatic islets limiting complement activation. 
Another function of C4BP appears to be neutralization of cytotoxic oligomers of IAPP due to its ability to enhance fibril formation.

Acknowledgments-We thank Frida Mohlin for expert technical help and Prof. Garred (Copenhagen University, Denmark) for the antibodies detecting ficolins.

\section{REFERENCES}

1. Westermark, P., Wernstedt, C., Wilander, E., Hayden, D. W., O'Brien, T. D., and Johnson, K. H. (1987) Amyloid fibrils in human insulinoma and islets of Langerhans of the diabetic cat are derived from a neuropeptidelike protein also present in normal islet cells. Proc. Natl. Acad. Sci. U.S.A. 84, 3881-3885

2. Lukinius, A., Wilander, E., Westermark, G. T., Engström, U., and Westermark, P. (1989) Co-localization of islet amyloid polypeptide and insulin in the B cell secretory granules of the human pancreatic islets. Diabetologia 32, 240-244

3. Kahn, S. E., D’Alessio, D. A., Schwartz, M. W., Fujimoto, W. Y., Ensinck, J. W., Taborsky, G. J., Jr., and Porte, D., Jr. (1990) Evidence of cosecretion of islet amyloid polypeptide and insulin by $\beta$-cells. Diabetes $39,634-638$

4. Butler, A. E., Janson, J., Bonner-Weir, S., Ritzel, R., Rizza, R. A., and Butler, P. C. (2003) $\beta$-Cell deficit and increased $\beta$-cell apoptosis in humans with type 2 diabetes. Diabetes 52, 102-110

5. Maloy, A. L., Longnecker, D. S., and Greenberg, E. R. (1981) The relation of islet amyloid to the clinical type of diabetes. Hum. Pathol. 12, 917-922

6. Jurgens, C. A., Toukatly, M. N., Fligner, C. L., Udayasankar, J., Subramanian, S. L., Zraika, S., Aston-Mourney, K., Carr, D. B., Westermark, P., Westermark, G. T., Kahn, S. E., and Hull, R. L. (2011) $\beta$-Cell loss and $\beta$-cell apoptosis in human type 2 diabetes are related to islet amyloid deposition. Am. J. Pathol 178, 2632-2640

7. Guardado-Mendoza, R., Davalli, A. M., Chavez, A. O., Hubbard, G. B., Dick, E. J., Majluf-Cruz, A., Tene-Perez, C. E., Goldschmidt, L., Hart, J., Perego, C., Comuzzie, A. G., Tejero, M. E., Finzi, G., Placidi, C., La Rosa, S., Capella, C., Halff, G., Gastaldelli, A., DeFronzo, R. A., and Folli, F. (2009) Pancreatic islet amyloidosis, $\beta$-cell apoptosis, and $\alpha$-cell proliferation are determinants of islet remodeling in type 2 diabetic baboons. Proc. Natl. Acad. Sci. U.S.A. 106, 13992-13997

8. Glabe, C. G. (2008) Structural classification of toxic amyloid oligomers. J. Biol. Chem. 283, 29639-29643

9. Rumora, L., Hadzija, M., Barisić, K., Maysinger, D., and Grubiić, T. Z. (2002) Amylin-induced cytotoxicity is associated with activation of caspase- 3 and MAP kinases. Biol. Chem. 383, 1751-1758

10. Anguiano, M., Nowak, R. J., and Lansbury, P. T., Jr. (2002) Protofibrillar islet amyloid polypeptide permeabilizes synthetic vesicles by a pore-like mechanism that may be relevant to type II diabetes. Biochemistry 41, $11338-11343$

11. Zraika, S., Hull, R. L., Verchere, C. B., Clark, A., Potter, K. J., Fraser, P. E., Raleigh, D. P., and Kahn, S. E. (2010) Toxic oligomers and islet $\beta$-cell death: guilty by association or convicted by circumstantial evidence? Diabetologia 53, 1046-1056

12. Ricklin, D., Hajishengallis, G., Yang, K., and Lambris, J. D. (2010) Complement: a key system for immune surveillance and homeostasis. Nat. Immunol. 11, 785-797

13. Klegeris, A., and McGeer, P. L. (2007) Complement activation by islet amyloid polypeptide (IAPP) and $\alpha$-synuclein 112. Biochem. Biophys. Res. Commun. 357, 1096-1099

14. Walport, M. J. (2001) Complement. First of two parts. N. Engl. J. Med. 344, $1058-1066$

15. Sjöberg, A. P., Trouw, L. A., and Blom, A. M. (2009) Complement activation and inhibition: a delicate balance. Trends Immunol. 30, 83-90

16. Ziccardi, R. J., and Tschopp, J. (1982) The dissociation properties of native C1. Biochem. Biophys. Res. Commun. 107, 618-623

17. Spitzer, D., Mitchell, L. M., Atkinson, J. P., and Hourcade, D. E. (2007) Properdin can initiate complement activation by binding specific target surfaces and providing a platform for de novo convertase assembly. J. Im- munol. 179, 2600-2608

18. Akiyama, H., Barger, S., Barnum, S., Bradt, B., Bauer, J., Cole, G. M., Cooper, N. R., Eikelenboom, P., Emmerling, M., Fiebich, B. L., Finch, C. E., Frautschy, S., Griffin, W. S., Hampel, H., Hull, M., Landreth, G., Lue, L., Mrak, R., Mackenzie, I. R., McGeer, P. L., O’Banion, M. K., Pachter, J., Pasinetti, G., Plata-Salaman, C., Rogers, J., Rydel, R., Shen, Y., Streit, W., Strohmeyer, R., Tooyoma, I., Van Muiswinkel, F. L., Veerhuis, R., Walker, D., Webster, S., Wegrzyniak, B., Wenk, G., and Wyss-Coray, T. (2000) Inflammation and Alzheimer's disease. Neurobiol. Aging 21, 383-421

19. Hillarp, A., and Dahlbäck, B. (1990) Cloning of cDNA coding for the $\beta$-chain of human complement component C4b-binding protein: sequence homology with the $\alpha$-chain. Proc. Natl. Acad. Sci. U.S.A. 87, $1183-1187$

20. Dahlbäck, B., and Stenflo, J. (1981) High molecular weight complex in human plasma between vitamin $\mathrm{K}$-dependent protein $\mathrm{S}$ and complement component C4b-binding protein. Proc. Natl. Acad. Sci. U.S.A. 78, 2512-2516

21. Sjöberg, A. P., Nyström, S., Hammarström, P., and Blom, A. M. (2008) Native, amyloid fibrils and $\beta$-oligomers of the C-terminal domain of human prion protein display differential activation of complement and bind $\mathrm{C} 1 \mathrm{q}$, factor $\mathrm{H}$, and $\mathrm{C} 4 \mathrm{~b}$-binding protein directly. Mol. Immunol. 45, 3213-3221

22. Trouw, L. A., Nielsen, H. M., Minthon, L., Londos, E., Landberg, G., Veerhuis, R., Janciauskiene, S., and Blom, A. M. (2008) C4b-binding protein in Alzheimer's disease: binding to Abeta1-42 and to dead cells. Mol. Immunol. 45, 3649-3660

23. Mollnes, T. E., Song, W. C., and Lambris, J. D. (2002) Complement in inflammatory tissue damage and disease. Trends Immunol. 23, 61-64.

24. Dahlbäck, B. (1983) Purification of human C4b-binding protein and formation of its complex with vitamin K-dependent protein S. Biochem. J. 209, 847-856

25. Blom, A. M., Kask, L., and Dahlbäck, B. (2003) CCP1-4 of the C4b-binding protein $\alpha$-chain are required for factor I mediated cleavage of complement factor C3b. Mol. Immunol. 39, 547-556

26. Tenner, A. J., Lesavre, P. H., and Cooper, N. R. (1981) Purification and radiolabeling of human C1q. J. Immunol. 127, 648-653

27. Pâques, E. P., Huber, R., Priess, H., and Wright, J. K. (1979) Isolation of the globular region of the subcomponent q of the $\mathrm{C} 1$ component of complement. Hoppe Seylers Z. Physiol. Chem. 360, 177-183

28. Reid, K. B. (1976) Isolation, by partial pepsin digestion, of the three collagen-like regions present in subcomponent Clq of the first component of human complement. Biochem. J. 155, 5-17

29. Blom, A. M., Kask, L., and Dahlbäck, B. (2001) Structural requirements for the complement regulatory activities of C4BP. J. Biol. Chem. 276, $27136-27144$

30. García de Frutos, P., Härdig, Y., and Dahlbäck, B. (1995) Serum amyloid P component binding to C4b-binding protein. J. Biol. Chem. 270, 26950-26955

31. Westermark, P., Engström, U., Johnson, K. H., Westermark, G. T., and Betsholtz, C. (1990) Islet amyloid polypeptide: pinpointing amino acid residues linked to amyloid fibril formation. Proc. Natl. Acad. Sci. U.S.A. 87, $5036-5040$

32. Betsholtz, C., Christmansson, L., Engström, U., Rorsman, F., Svensson, V., Johnson, K. H., and Westermark, P. (1989) Sequence divergence in a specific region of islet amyloid polypeptide (IAPP) explains differences in islet amyloid formation between species. FEBS Lett. 251, 261-264.

33. Larsson, A., Söderberg, L., Westermark, G. T., Sletten, K., Engström, U., Tjernberg, L. O., Näslund, J., and Westermark, P. (2007) Unwinding fibril formation of medin, the peptide of the most common form of human amyloid. Biochem. Biophys. Res. Commun. 361, 822-828

34. Manders, E. M., Stap, J., Brakenhoff, G. J., van Driel, R., and Aten, J. A. (1992) Dynamics of three-dimensional replication patterns during the Sphase, analysed by double labelling of DNA and confocal microscopy. J. Cell Sci. 103, 857-862

35. Pitsavos, C., Tampourlou, M., Panagiotakos, D. B., Skoumas, Y., Chrysohoou, C., Nomikos, T., and Stefanadis, C. (2007) Association between low-grade systemic inflammation and type 2 diabetes mellitus among men and women from the ATTICA Study. Rev. Diabet. Stud. 4, 98-104 


\section{IAPP and Complement}

36. Ebeling, P., Teppo, A. M., Koistinen, H. A., and Koivisto, V. A. (2001) Concentration of the complement activation product, acylation-stimulating protein, is related to $C$-reactive protein in patients with type 2 diabetes. Metabolism 50, 283-287

37. Köhl, J. (2006) Drug evaluation: the C5a receptor antagonist PMX-53. Curr. Opin. Mol. Ther. 8, 529-538

38. Webster, S., Bonnell, B., and Rogers, J. (1997) Charge-based binding of complement component $\mathrm{C} 1 \mathrm{q}$ to the Alzheimer amyloid $\beta$-peptide. Am. J. Pathol. 150, 1531-1536

39. Head, E., Azizeh, B. Y., Lott, I. T., Tenner, A. J., Cotman, C. W., and Cribbs, D. H. (2001) Complement association with neurons and $\beta$-amyloid deposition in the brains of aged individuals with Down syndrome. Neurobiol. Dis. 8, 252-265
40. Rostagno, A., Revesz, T., Lashley, T., Tomidokoro, Y., Magnotti, L., Braendgaard, H., Plant, G., Bojsen-Møller, M., Holton, J., Frangione, B., and Ghiso, J. (2002) Complement activation in chromosome 13 dementias. Similarities with Alzheimer's disease. J. Biol. Chem. 277, 49782-49790

41. Jaikaran, E. T., and Clark, A. (2001) Islet amyloid and type 2 diabetes: from molecular misfolding to islet pathophysiology. Biochim. Biophys. Acta 1537, 179-203

42. Hulbert, E. M., Smink, L. J., Adlem, E. C., Allen, J. E., Burdick, D. B., Burren, O. S., Cassen, V. M., Cavnor, C. C., Dolman, G. E., Flamez, D., Friery, K. F., Healy, B. C., Killcoyne, S. A., Kutlu, B., Schuilenburg, H., Walker, N. M., Mychaleckyj, J., Eizirik, D. L., Wicker, L. S., Todd, J. A., and Goodman, N. (2007) T1DBase: integration and presentation of complex data for type 1 diabetes research. Nucleic Acids Res. 35, D742-746 